\title{
The role of the particle size distribution in assessing aerosol composition effects on simulated droplet activation
}

\author{
D. S. Ward ${ }^{1}$, T. Eidhammer ${ }^{2}$, W. R. Cotton ${ }^{1}$, and S. M. Kreidenweis ${ }^{1}$ \\ ${ }^{1}$ Atmospheric Science, Colorado State University, Fort Collins, Colorado, USA \\ ${ }^{2}$ National Center for Atmospheric Research, Boulder, Colorado, USA
}

Received: 21 January 2010 - Published in Atmos. Chem. Phys. Discuss.: 11 February 2010

Revised: 22 May 2010 - Accepted: 9 June 2010 - Published: 21 June 2010

\begin{abstract}
Variations in the chemical composition of atmospheric aerosols alter their hygroscopicity and can lead to changes in the cloud-active fraction of the aerosols, or cloud condensation nuclei (CCN) number concentration. To investigate the importance of this effect under different atmospheric conditions, cloud droplet formation was simulated with a Lagrangian parcel model. Initial values of updraft speed and temperature were systematically varied along with aerosol number concentration, size and hygroscopicity (represented by the hygroscopicity parameter, $\kappa$ ). A previous study classifies the sensitivity of CCN activity to compositional changes based on the supersaturation reached in the parcel model. We found that these classifications could not be generalized to a range of aerosol size distribution median radii. Instead, variations in sensitivity with size depend on the location of the dry critical radius for droplet activation relative to the size distribution median radius. The parcel model output was used to construct droplet activation lookup tables based on $\kappa$ that were implemented in the Regional Atmospheric Modeling System (RAMS) microphysical scheme. As a first application of this system, aerosol hygroscopicity and size were varied in a series of RAMS mesoscale simulations designed to investigate the sensitivity of a mixed-phase orographic cloud case to the parameter variations. Observations from a recent field campaign in northwestern Colorado provided the basis for the aerosol field initializations. Model results show moderate sensitivity in the distribution of total case precipitation to extreme changes in $\kappa$, and minimal sensitivity to observed changes in estimated $\kappa$. The impact of varying aerosol hygroscopicity diminished with increasing median radius, as expected from the parcel model results. The conclusions drawn from these
\end{abstract}

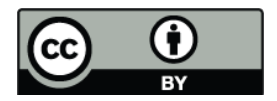

Correspondence to: D. S. Ward (dsward@atmos.colostate.edu) simulations could simplify similar research in other cloud regimes by defining the need, or lack of need, for detailed knowledge of aerosol composition.

\section{Introduction}

Köhler theory predicts that the chemical composition of an atmospheric particle partly determines its ability to activate as a cloud droplet. Changes in the composition of a droplet nucleus can alter the supersaturation required for activation, or critical supersaturation $\left(S_{c}\right)$, of the solution droplet through the solute effect and surface tension effects (Pruppacher and Klett, 1997). In these ways, aerosol composition can influence cloud condensation nuclei (CCN) number concentrations. In fact, unknown or variable aerosol composition is often cited as the main source of error in $\mathrm{CCN}$ closure studies that attempt to model observed $\mathrm{CCN}$ activity using observed aerosol characteristics (e.g., Cantrell et al., 2001; Rissman et al., 2006; Bougiatioti et al., 2009).

While laboratory and field studies have clearly shown that $\mathrm{CCN}$ activity depends on aerosol composition, the degree of the dependence for atmospheric aerosol has been the subject of recent debate. Several single-site observational studies have found that $\mathrm{CCN}$ number concentrations active at a specified supersaturation can be predicted accurately without detailed knowledge of the aerosol chemical composition (Dusek et al., 2006; Ervens et al., 2007; Medina et al., 2007). In contrast, the measurements of Hudson (2007) and Quinn et al. (2008) show substantial variability in the $\mathrm{CCN}$ activity of aerosol sampled in different air masses of both continental and marine origin.

Since simplifications of the complex composition of ambient aerosol are sought for modeling applications, the debate about the level of detail to which composition must be known

Published by Copernicus Publications on behalf of the European Geosciences Union. 
has important implications for studies of aerosol direct and indirect effects on regional and global scales (Dusek et al., 2006). Recently, Reutter et al. (2009) reported the results from a parcel model study of aerosol composition effects on $\mathrm{CCN}$ activity in pyrocumulus cloud conditions that simplified the treatment of compositional dependence by defining environmental regimes. These regimes were based on the ratio of updraft speed $w$ to particle number concentration $N_{c n}$. Conditions with low values of this ratio were classified as updraft-limited $\left(w / N_{c n}<\approx 10^{-4} \mathrm{~m} \mathrm{~s}^{-1} /\left(\mathrm{cm}^{-3}\right)\right)$ and high values as aerosol-limited $\left(w / N_{c n}>\approx 10^{-3} \mathrm{~m} \mathrm{~s}^{-1} /\left(\mathrm{cm}^{-3}\right)\right)$ with a transition regime between these two extremes $\left(10^{-4} \mathrm{~m} \mathrm{~s}^{-1} /\left(\mathrm{cm}^{-3}\right)<\approx w / N_{c n}<\approx 10^{-3} \mathrm{~m} \mathrm{~s}^{-1} /\left(\mathrm{cm}^{-3}\right)\right)$. The median radius of the input lognormal aerosol size distribution was held fixed. They found that changes in composition had an insignificant effect on droplet activation in the aerosollimited regime and a moderate impact on droplet number concentrations for updraft-limited conditions.

In Reutter et al. (2009), as in previous studies (e.g, Feingold, 2003; Rissman et al., 2004; McFiggans et al., 2006), a sensitivity parameter was defined to describe the effects of perturbations in aerosol or environmental characteristics on droplet number concentrations or droplet effective radii. We adopt the same convention as Reutter et al. (2009), who defined the sensitivity parameter as the logarithmic change in droplet number concentration, $N_{d}$, with the logarithmic change in a specified chemical or physical parameter $X_{i}$ :

$S\left(X_{i}\right)=\frac{\partial \ln N_{d}}{\partial \ln X_{i}}$

In this paper, we consider the Reutter et al. (2009) environmental regimes, but vary the lognormal median aerosol radius used to initialize the parcel model, to examine the role of particle size on $\mathrm{CCN}$ activity with changing composition. The results of the simulations were also used to construct droplet activation lookup tables with aerosol hygroscopicity as an independent variable, expanding on the original design of Saleeby and Cotton (2004) which has been applied in several cloud-scale modeling studies (e.g., van den Heever and Cotton, 2007; Cheng et al., 2009). These lookup tables were implemented in the Colorado State University version of the Regional Atmospheric Modeling System (RAMS; Cotton et al., 2003). Here we use the new droplet activation scheme to investigate the susceptibility of a simulated mixed-phase orographic cloud to variations in aerosol characteristics.

The distribution of precipitation from orographic clouds in which liquid and ice particles coexist is determined largely by the amount of riming that occurs in the cloud (Saleeby et al., 2007). Theoretically, the riming efficiency is computed from the size of the collector ice crystal and the size of the cloud droplets being collected, and decreases rapidly for droplets with diameters below $10 \mu \mathrm{m}$ (Pruppacher and Klett, 1997). Therefore, an increase in CCN, if resulting in smaller droplet sizes, can decrease riming, leading to suppressed precipitation totals on the windward side of the orography and increased accumulated precipitation on the leeward slope as unrimed, slowly falling snow crystals are advected further downstream (Saleeby et al., 2009). This "spillover" effect has also been shown in two-dimensional simulations of liquid-phase orographic clouds, although in these cases the precipitation redistribution is attributed to a slowing of the rate of cloud droplet collection or autoconversion (Muhlbauer and Lohmann, 2008; Lynn et al., 2007). The modeling work of Saleeby et al. (2009) on this topic has shown the impacts of varying the initial model $N_{c n}$ on mixed-phase orographic cloud microphysics. With the simulations in our study we aim to determine the importance of the model aerosol size and hygroscopicity on these same cloud systems by applying the expanded droplet activation scheme to a case observed during the Inhibition of Snowfall by Pollution Aerosols (ISPA) II field campaign in February 2007. Aerosol size and droplet activation data collected during this study provided representative values for the initialization of RAMS in these simulations. The parcel model results and sensitivity studies are used to make recommendations for estimating the potential impact of variations in aerosol composition on cloud droplet number concentration in observed cloud regimes.

\section{Parcel model simulations}

\subsection{Model setup}

To simulate the activation of cloud droplets we make use of a Lagrangian parcel model. The parcel model used for this study was introduced by Heymsfield and Sabin (1989) and has been described thoroughly by Saleeby and Cotton (2004). The parcel model follows a simulated air parcel as it is lifted with an initial updraft velocity and becomes supersaturated with respect to water. Initially (time, $t,<0$ ), the parcel contains a prescribed distribution of dry aerosol that is divided into 100 size bins centered on an assigned median radius. The distribution is assumed to be lognormal with shape parameter $\sigma_{g}=1.8$. This value for $\sigma_{g}$ was chosen to maintain consistency with the existing RAMS lookup tables (Saleeby and Cotton, 2004). The assigned $\sigma_{g}=1.8$ falls within the range tested by Antilla and Kerminen (2007) that was based on observed aerosol size distributions. While being lifted, activation of haze particles and the growth of droplets in each size bin along with expressions for the change in temperature, pressure, air density and liquid water content with time are solved iteratively with the Variable-coefficient Ordinary Differential Equation (VODE) solver (Brown et al., 1989). The time resolution of these computations is determined within the VODE solver but the output from all simulations is standardized with a longer, external time step. This time step was set to $250 \mathrm{~cm} w^{-1}$ and is therefore dependent on the model vertical velocity. After reaching its maximum supersaturation $\left(S_{\max }\right)$, the parcel is lifted a further $50 \mathrm{~m}$ to 
Table 1. Initial values for the parcel model simulations.

\begin{tabular}{llllllllll}
\hline$T\left({ }^{\circ} \mathrm{C}\right)$ & -30 & -20 & -10 & 0 & 10 & 20 & 30 & & \\
\hline $\mathrm{N}_{c n}\left(\mathrm{~cm}^{-3}\right)$ & 10 & 31.6 & 100 & 316 & 1000 & 3600 & $1 \mathrm{e} 5$ & & \\
$\mathrm{w}(\mathrm{m} / \mathrm{s})$ & 0.01 & 0.032 & 0.1 & 0.316 & 1.0 & 3.16 & 10 & 31.6 & 100 \\
$r_{g}(\mu \mathrm{m})$ & 0.01 & 0.015 & 0.02 & 0.03 & 0.04 & 0.06 & 0.08 & 0.12 & 0.16 \\
& 0.24 & 0.36 & 0.48 & 0.64 & 0.96 & 1.28 & & & \\
$\kappa$ & $1 \mathrm{e}-5$ & $1 \mathrm{e}-4$ & 0.001 & 0.01 & 0.03 & 0.06 & 0.1 & 0.2 & 0.25 \\
& 0.3 & 0.35 & 0.4 & 0.45 & 0.5 & 0.55 & 0.6 & 0.65 & 0.7 \\
& 0.75 & 0.8 & 0.85 & 0.9 & 1.0 & 1.1 & 1.28 & & \\
\hline
\end{tabular}

provide ample time for activated droplets to grow. This simple parcel representation of the initial stage of cloud development only includes liquid-phase hydrometeor formation. The production of hydrometeors other than cloud droplets is not considered, nor are sedimentation processes that would remove water mass from the parcel.

The percentage of the initial $N_{c n}$ that activates into cloud droplets in the parcel model depends on a number of input variables that describe the initial aerosol and environmental conditions. To limit the number of combinations of initial settings, Saleeby and Cotton (2004) restricted the independent variables to four: temperature $T, w, N_{c n}$, and the aerosol distribution number median radius $r_{g}$, and assumed a constant aerosol composition of ammonium sulfate or sodium chloride with a constant insoluble fraction. We have extended this scheme to include aerosol hygroscopicity as a fifth independent variable.

The incorporation of aerosol hygroscopicity was made possible by modifications made to the original Heymsfield and Sabin (1989) parcel model by Eidhammer et al. (2009). Their model development work included the introduction of the hygroscopicity parameter $(\kappa)$ (Petters and Kreidenweis, 2007) into the saturation ratio formula for liquid droplets. The hygroscopicity factor is a proxy for chemical composition, and was tabulated by Petters and Kreidenweis (2007) for many aerosol constituents; it can also be computed for internal mixtures of assumed components or determined empirically from experiments. The research reported here includes only one aerosol mode characterized by a single value of $\kappa$ for each simulation. As in previous studies (e.g., Ervens et al., 2007; McFiggans et al., 2006; Rissman et al., 2004), we note the inaccuracy of ignoring quasi-internal or external mixing states but also recognize the difficulties in modeling such aerosol. Cubison et al. (2008) investigated the importance of the representative mixing state in modeling $\mathrm{CCN}$ activation in an urban setting. They found that CCN prediction was significantly improved by assuming externally mixed aerosol and conclude that using an internal mixture for modeling can lead to both over and under-predictions of $\mathrm{CCN}$. While it could be expected that freshly-emitted aerosol would be externally mixed, McFiggans et al. (2006) notes that the mixing state of most ambient aerosol can be considered at least quasi-internal.

With the Eidhammer et al. (2009) changes in place, the parcel model was run for all combinations of initial $T, w$, $N_{c n}$, and $r_{g}$ used in Saleeby and Cotton (2004), given in Table 1 , and for 25 values of $\kappa$ between 0.00001-1.28. These values of $\kappa$ were selected to span observed magnitudes of aerosol hygroscopicity in both urban and remote locations. Andreae and Rosenfeld (2008) reported typical continental values for $\kappa$ of 0.2 to 0.4 with few observations below 0.1 , and 1.28 is the reported value for $\mathrm{NaCl}$ (Petters and Kreidenweis, 2007). The ranges chosen for the remaining variables include extreme values in order to capture all conditions that could potentially be encountered in RAMS simulations. The initial pressure, $600 \mathrm{mb}$, and initial relative humidity, $99 \%$, were kept the same for all model runs. $S_{\max }$ achieved in the parcels, and the resulting $N_{d}$, were recorded.

In general, the sensitivity of droplet activation to changing $\kappa$ has been shown to decrease substantially with increasing $\kappa$ (Petters and Kreidenweis, 2007). For this reason, several of the high- $\kappa$ parcel model results can be disregarded for construction of look-up tables while maintaining sufficient resolution of the potential impacts on activated fraction. Reutter et al. (2009) showed that, in particular, this sensitivity is greatest below $\kappa=0.1$, although samples of such nonhygroscopic aerosol are seldom collected in the atmosphere. Lookup tables for the following twelve values of $\kappa$ were included in the RAMS droplet activation scheme: 0.00001, $0.01,0.03,0.06,0.1,0.2,0.25,0.35,0.45,0.6,0.9,1.28$. When intermediate values of $\kappa$ occur in the course of a simulation, $N_{d}$ is determined by linear interpolation between the activated fraction for the adjacent higher and lower $\kappa$ lookup tables.

\subsection{Parcel model results}

As $\kappa$ is increased in the parcel model, the simulated particles become more hygroscopic and equivalent particle sizes will activate at lower supersaturations. Thus, increases in $\kappa$ allow for particles with incrementally smaller sizes to reach the critical threshold and a larger portion of the aerosol 

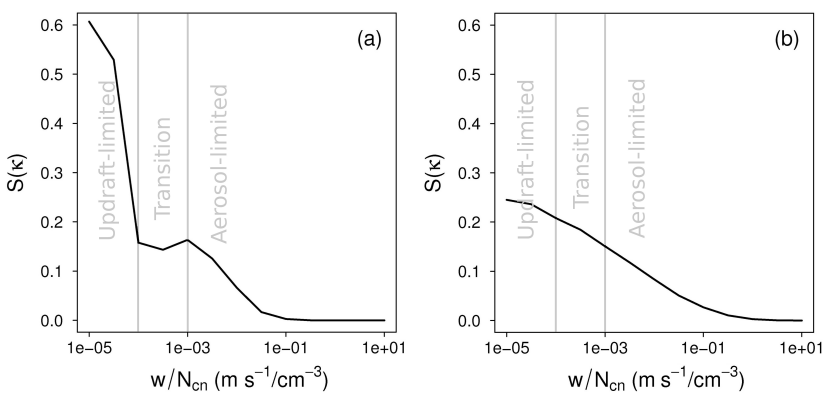

Fig. 1. The sensitivity of the droplet number to $\kappa, S(\kappa)$, computed from parcel model output, as a function of the ratio $w / N_{c n}$, for $\kappa=0.2$ to 0.5 . The sensitivities were averaged over all initial values of $T$. Results are shown for (a) input aerosol size distributions with $r_{g}=0.06 \mu \mathrm{m}$, and (b) averaged over all initial values of $r_{g}$. The Reutter et al. (2009) regimes are indicated.

distribution to activate. Reutter et al. (2009) found that the relationship between an increase in $\kappa$ and an increase in $N_{d}$ was not constant, but varied with changes in the ratio of the initial updraft speed to the initial particle number $\left(w / N_{c n}\right)$. In our study, $w / N_{c n}$ will also be used to compare the parcel model output to these previous results. The $w / N_{c n}$ quantity is especially useful for classifying different parcel model environments, as it is an able predictor of the model $S_{\max }$. In our simulations, between values of $w / N_{c n}=10^{-6} \mathrm{~m} \mathrm{~s}^{-1} /\left(\mathrm{cm}^{-3}\right)$ and $w / N_{c n}=10^{-1} \mathrm{~m} \mathrm{~s}^{-1} /\left(\mathrm{cm}^{-3}\right)$, the $S_{\max }$ (averaged over all initial $r_{g}$ and $T$ ) was highly correlated with $w / N_{c n}$ in a positive sense (linear correlation coefficient $r=0.93$ ).

Figure 1a shows how changes in aerosol composition affect CCN activity as $w / N_{c n}$ increases in the parcel model, for an initial $r_{g}=0.06 \mu \mathrm{m}$. We compute the dependent variable, $S(\kappa)$, using the method shown by Feingold (2003) and summarized as follows. Parcel model predictions of $N_{d}$ are plotted against $\kappa$ on a log-log plot. A linear relationship is fitted to the plot using regression and the resulting slope of the line is understood to be $S(\kappa)$ for the specified range in $\kappa$ and given initial conditions. Reutter et al. (2009) use this approach but plot values of $N_{d}$ for each initial $\kappa$ that have been averaged over all initial conditions and name the modified parameter $\bar{S}(\kappa)$. In our simulations, several combinations of initial $w$ and $N_{c n}$ result in the same value of $w / N_{c n}$, meaning multiple values of $S(\kappa)$ occur at the same $w / N_{c n}$. Additionally, several values of $S(\kappa)$ are computed at the same $w / N_{c n}$ but for different initial $T$. These are averaged to give the single value of $S(\kappa)$ at each $w / N_{c n}$ shown in Fig. 1a. The range in $\kappa$ for this portion of the analysis, 0.2 to 0.5 , was chosen to incorporate the typical hygroscopicity values for continental aerosol. It extends the range suggested by Andreae and Rosenfeld (2008) for continental airmass modeling ( 0.2 to 0.4 ) to include the majority of observations compiled by Hudson (2007) in continental regions, reported as $\kappa=0.33$ $+/-0.15$ by Andreae and Rosenfeld (2008).
The updraft and aerosol-limited regimes are clearly discerned in Fig. 1a and compare well to the Reutter et al. (2009) regime designations, also based on $r_{g}=0.06 \mu \mathrm{m}$, despite some differences between our analysis and that of Reutter et al. (2009). They used a broader range of $\kappa$, from 0.001 to 0.6 , and focused on high updraft and high particle number conditions, characteristic of pyrocumulus clouds. In our runs, the change in $\kappa$ from 0.2 to 0.5 leads to the highest values of $S(\kappa)$ for $w / N_{c n}$ less than $10^{-4} \mathrm{~m} \mathrm{~s}^{-1} /\left(\mathrm{cm}^{-3}\right)$, defined as the updraft-limited regime. When the model is initialized as aerosol-limited $\left(w / N_{c n}>10^{-3} \mathrm{~m} \mathrm{~s}^{-1} /\left(\mathrm{cm}^{-3}\right)\right), S(\kappa)$ is small and diminishes to near zero with increasing $w / N_{c n}$. In this regime, as noted by Reutter et al. (2009), the parcel reaches a $S_{\max }$ great enough to activate nearly $100 \%$ of the particles in the given distribution at all values of $\kappa$ and for all initial values of $w$. Thus, compositional effects are rendered insignificant in these highly supersaturated model environments.

To extend this analysis to a range of size distributions we compare the results of simulations with different initial $r_{g}$. Fifteen values of $r_{g}$ between $0.01 \mu \mathrm{m}$ and $0.96 \mu \mathrm{m}$ were used to initialize the parcel model. Figure $1 \mathrm{~b}$ shows the same quantities as in Fig. 1a, but averaged over the range of initial $r_{g}$. The resulting curve exhibits the same three-regime structure as in Fig. 1a, but the divisions between the regimes are no longer distinct. The sharp decrease in $S(\kappa)$ between the updraft-limited and transition regimes has been reduced, and some sensitivity to the change in $\kappa$ extends well into the aerosol-limited regime.

A better demonstration of the effect of changing the size distribution is given in Fig. 2, which displays the change in $S(\kappa)$ with increasing $r_{g}$ while holding $w / N_{c n}$ constant. Previous studies have evaluated $S(\kappa)$ and sensitivity to other measures of composition as a singular value representative of the entire initial parameter space (e.g., Rissman et al., 2004; Reutter et al., 2009). This figure shows that $S(\kappa)$ varies significantly within that parameter space, in this case with respect to $r_{g}$. In the aerosol-limited regime (Fig. 2a), $S(\kappa)$ is small for $r_{g}=0.06 \mu \mathrm{m}$ but increases to $S(\kappa)=0.35$ below that size when $\sigma_{g}=1.8$. For these small aerosols, composition affects $\mathrm{CCN}$ activity even in the aerosol-limited regime. A similar trend is apparent for the transition regime shown in Fig. 2b, although the high $S(\kappa)$ values are shifted to higher median radii.

Finally, for the updraft-limited regime illustrated in Fig. 2c, the highest sensitivity extends to even larger median radii, tapering off above $r_{g}=0.15 \mu \mathrm{m}$. The non-monotonic path of the sensitivity curve in Fig. $2 \mathrm{c}$ could be the result of non-trivial variations in the difference between $S_{\max }$ reached for the lower $\kappa$ limit $(\kappa=0.2)$ and for the upper $\kappa$ limit $(\kappa=0.5)$. Solution drops formed by more hygroscopic or larger particles remain in equilibrium with their environment at a lower saturation ratio, leading to the variations (Saleeby and Cotton, 2004). The difference in $S_{\max }$ is amplified and, therefore, becomes more important as $r_{g}$ increases. This effect, in combination with already enhanced 

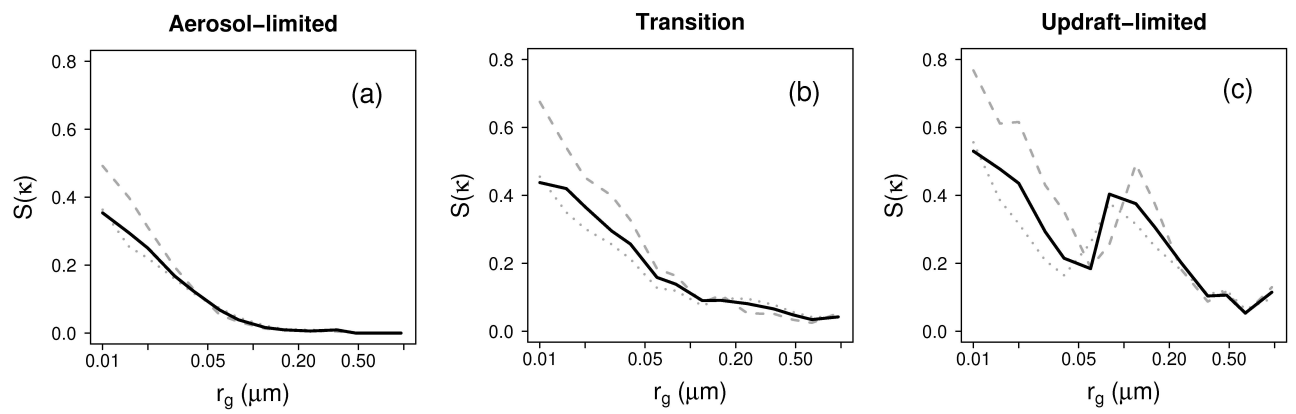

Fig. 2. $S(\kappa)$ computed from parcel model output for $\kappa=0.2$ to 0.5 as a function of the choice of initial $r_{g}$. The sensitivities were averaged over all initial values of $T$. Each panel displays output from simulations initialized with a single value of $w / N_{c n}$ set to (a) $1 \mathrm{e}-02$, (b) $1 \mathrm{e}-03$, and (c) $1 \mathrm{e}-04 \mathrm{~m} \mathrm{~s}^{-1} / \mathrm{cm}^{-3}$. Results from simulations at all three values of $\sigma_{g}$ are plotted as a dashed grey line $\left(\sigma_{g}=1.5\right)$, a solid black line $\left(\sigma_{g}=1.8\right)$, and a dotted grey line $\left(\sigma_{g}=2.1\right)$.

sensitivity at larger values of $r_{g}$ in the updraft-limited regime (Fig. 2c), could have caused the apparent maximum in $S(\kappa)$ near $r_{g}=0.1 \mu \mathrm{m}$ that occurred for all values of initial size distribution shape parameters. Of course, unstable behavior in the parcel model, which has been reported in such models at very low supersaturations (e.g. Reutter et al., 2009), could also be a factor.

The parcel model simulations were repeated for $\sigma_{g}=1.5$ and $\sigma_{g}=2.1$ to investigate the impact of the size distribution shape on these results. Antilla and Kerminen (2007) concluded that, for low updraft velocities, the size distribution shape could be just as important as the median radius for determining sensitivity to compositional changes. Here, values of $S(\kappa)$ for the different distribution shapes are given by the dashed and dotted lines in Fig. 2. The narrowest size distribution $\left(\sigma_{g}=1.5\right)$ shows the greatest values of sensitivity but trends the same as the other curves, as given by the dashed and dotted lines in Fig. 2. The values of $S(\kappa)$ plotted in Fig. 2 also suggest that shape parameter variations are more important for small $r_{g}$ and no more or less important in the different regimes. In all Fig. 2 plots, the sensitivity to changes in $\kappa$ varies significantly within the $w / N_{c n}$ regimes. Altogether, the results in this figure show that $w / N_{c n}$, or supersaturationbased regimes, cannot fully predict the compositional dependence of CCN activity independently of the $r_{g}$.

\subsection{Relationship between $r_{\mathrm{g}}$ and $S(\kappa)$}

The analysis of the $w / N_{c n}$ regimes and the sensitivity parameter imply a role of the size distribution in predicting the dependence of $\mathrm{CCN}$ activity on aerosol composition. In their review of droplet activation theory, McFiggans et al. (2006) state that CCN activity is determined by the number of particles and the gradient of the size distribution, at the critical radius $\left(r_{c}\right)$ or range in $r_{c}$ under investigation. They note that this idea can be attributed to Twomey (1959) whose powerlaw representation of $\mathrm{CCN}$ clearly demonstrates the influence of size distribution parameters over activated fraction.

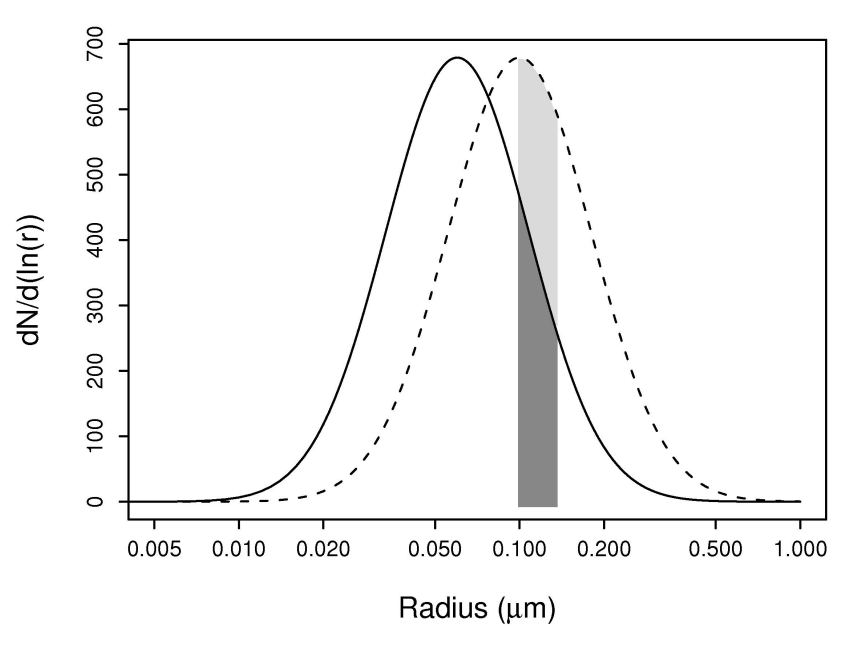

Fig. 3. Representation of the initial lognormal distributions of aerosol used in the parcel model for $r_{g}=0.06 \mu \mathrm{m}$ (solid) and $r_{g}=0.10 \mu \mathrm{m}$ (dashed). Each distribution assumes $N_{c n}=1000 \mathrm{~cm}^{-3}$ and $\sigma_{g}=1.8$. The shaded region shows the additional number of particles that would activate in each distribution if $\kappa$ were increased from 0.2 to 0.5 in an environment with $S_{\max }=0.165 \%$.

This influence can be shown for lognormal representations of aerosol size distributions as well.

Figure 3 illustrates the impact of the initial size parameter $r_{g}$ on $S(\kappa)$. The two input aerosol distributions are assumed to have $\kappa=0.2$, and the effect of changing this to $\kappa=0.5$ is evaluated. The shifts in critical dry size for this $\kappa$ change, corresponding to a selected $S_{c}$ (chosen as $S_{c}=0.165 \%$ ), are indicated. For the distribution with $r_{g}=0.10 \mu \mathrm{m}, S(\kappa)=0.14$ (here, $S(\kappa)$ is computed simply by differencing the logarithm of $N_{d}$ at each $\kappa$ and dividing by the logarithm of the fixed fractional change in $\kappa$, see Eq. 1), but the value of this parameter increases to 0.59 for $r_{g}=0.06 \mu \mathrm{m}$ due to the shift of the distribution median relative to the $r_{c}$ of the given supersaturated environment. Of course, in the parcel model, critical supersaturation would not be identical when $\kappa$ is modified, 
even for the same updraft velocity, tending to somewhat dampen out these differences (Rissman et al., 2006).

As suggested in Fig. 3, the variability of the compositional-dependence of $N_{d}$ is explained, in large part, by the location of the $r_{c}$ on the size distribution function of an aerosol population. For the lognormal size distribution function, the relative location of $r_{c}$ can be represented by the percentage of particles in the size distribution smaller than the stated $r_{c}$. This percentage can be expressed by evaluating the normalized cumulative size distribution function at radius $r=r_{c}$ :

$N(r c)=\frac{1}{2}+\frac{1}{2} \operatorname{erf}\left\{\frac{\ln \left(r_{c} / r_{g}\right)}{\sqrt{2} \ln \sigma_{g}}\right\}$

where erf is the error function and $N\left(r_{c}\right)$ is the fraction of particles smaller than $r_{c}$ for the given size distribution parameters $r_{g}$ and $\sigma_{g}$.

To determine $N\left(r_{c}\right)$ a cumulative distribution function was created for each initial value of $r_{g}$ used in the parcel model and each value of $\sigma_{g}\left(\sigma_{g}=1.5,1.8,2.1\right)$. Then, $r_{c}$ was computed using Eq. (10) from Petters and Kreidenweis (2007) for every combination of initial $N_{c n}, w, T$, and $r_{g}$, but for the fixed range in $\kappa, 0.2$ to 0.5 . The $S_{\max }$ reached in each simulation was used as the $S_{c}$ required for calculating $r_{c}$. The final $r_{c}$ was taken as the average between the $r_{c}$ for initial $\kappa=0.5$ and the $r_{c}$ for initial $\kappa=0.2$, for each combination of the other initial conditions. The span of particle size between $r_{c}$ computed for $\kappa=0.5$ and $\kappa=0.2$ (in Fig. 3, the width of the shaded region along the $\mathrm{x}$-axis) is not constant but varies with the environmental supersaturation and with $\kappa$ itself. As shown by Petters and Kreidenweis (2007), the change in $r_{c}$ for a fixed range in $\kappa$ increases with decreasing supersaturation.

The $r_{c}$, computed as explained above for every combination of $N_{c n}, w, T$, and $r_{g}$, was used to solve the cumulative size distribution function with the corresponding $r_{g}$. The resulting $N\left(r_{c}\right)$ values are positively correlated with $S(\kappa)$, which is consistent with an increase in $r_{c}$ relative to $r_{g}$ leading to an increase in the sensitivity of $\mathrm{CCN}$ activity to changes in $\kappa$. The computed Pearson linear correlation coefficients, $\mathrm{r}=0.80,0.82,0.85$ for $\sigma_{g}=1.5,1.8,2.1$ respectively, suggest that the predictive ability of $N\left(r_{c}\right)$ is strong for the entire range of varied initial conditions, including median radius. Therefore, for a fixed $r_{g}, S(\kappa)$ can be predicted from $r_{c}$ or, for a known $\kappa$ range, from $S_{c}$ as shown by Reutter et al. (2009). However, the inverse is also true. For a fixed $S_{c}$ and a known $\kappa$ range, the sensitivity to changes in $\kappa$ depends on the initial $r_{g}$. This result is, perhaps, intuitive, but it is also instructive. It suggests that for cloud regimes with characteristic supersaturations the importance of aerosol composition for droplet activation can be anticipated if basic aerosol size and source data are known. Of course, it is important to remember that these conclusions are derived from simulations that assumed a perfect internal mixture of aerosol and known uni-modal size distribution function, conditions that do not apply universally.

\section{Sensitivity experiment}

As an initial application of the $\kappa$-based lookup tables, and to test the role of the particle size distribution and aerosol hygroscopicity, sensitivity simulations were carried out centered around a mixed-phase orographic cloud case study for which aerosol size and droplet activation data were known. The sensitivity study was run with RAMS, which is well suited for simulating mixed-phase cloud systems owing to a sophisticated bin-emulating, bulk microphysics package (Saleeby and Cotton, 2008). Recently this was enhanced by the inclusion of a binned method for representing the riming process that was shown to improve the prediction of riming efficiencies (Saleeby and Cotton, 2008). RAMS predicts the cloud droplet distribution mixing ratio and number concentration (Saleeby and Cotton, 2004) and also predicts two moments of the distributions for rain, hail, pristine ice, snow, aggregates and graupel (Cotton et al., 2003). The formation of ice crystals by homogeneous and heterogeneous freezing, as well as secondary ice production are treated as described by Saleeby et al. (2009) with a vertically-decreasing profile of ice nuclei (IN) number concentration.

\subsection{Experimental design}

An orographic snowstorm that occurred over the Park Range in northwestern Colorado during 11-12 February 2007 was chosen as the case for this sensitivity study. Orographic clouds in this region form with westerly or northwesterly flow which induces the greatest uplift over the north-south running topography. In the absence of a frontal system, this flow is often forced by the presence of a mid-level ridge to the west and a developing lee trough to the east, together setting up a strong cross-barrier pressure gradient over the Park Range (Rauber et al., 1986). The 11-12 February 2007 storm formed under these conditions. It was characterized by a sustained period of high liquid water content (LWC), especially after 00:00 GMT on 12 February, and persistent precipitation of heavily rimed snow crystals (Saleeby et al., 2009). It has been hypothesized by Borys et al. (2000) that higher LWC mixed-phase orographic clouds are more sensitive to changes in CCN number concentration. Also, Saleeby et al. (2009) found that mixed-phase orographic storms that contain large supercooled droplet sizes, therefore riming efficiently, are more susceptible to the impacts of increasing $\mathrm{CCN}$ number concentration. For these reasons, the 11-12 February 2007 storm provides an excellent test case for examining the effects of a variable aerosol population.

To represent realistic variations in aerosol in these simulations, observations from the ISPA field campaign were used as the basis for the model initializations. Aerosol 

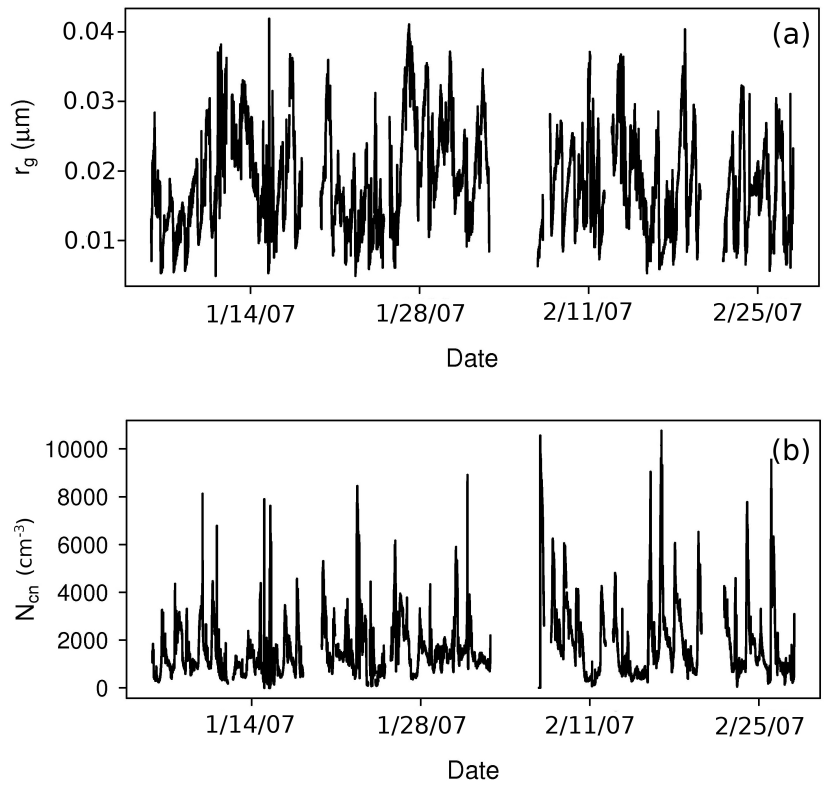

Fig. 4. Time series of (a) $r_{g}$ and (b) $N_{c n}$ estimated from observations collected during the ISPA campaign at SPL in 2007. Note that $r_{g}$ is estimated by fitting a single lognormal mode to the aerosol size distribution data. $N_{c n}$ was derived from the sum of all aerosol observed by the SMPS and APS.

number concentration and size distribution data were collected from 6 January 2007 to 28 February 2007 using a scanning mobility particle sizer (SMPS) and an aerodynamic particle size spectrometer (APS) located at the Desert Research Institute (DRI) Storm Peak Laboratory (SPL). SPL is located at an elevation of $3210 \mathrm{~m}$ above mean sea level atop the southern extent of the Park Range and is often above cloud base during winter orographic storms (Borys and Wetzel, 1997). The SMPS measured particle radii between 0.0044 and $0.17 \mu \mathrm{m}$ and the APS measured larger particles with radii between 0.25 and $10.3 \mu \mathrm{m}$. Total $N_{c n}$ was estimated as the sum of particles observed by the SMPS and APS. In addition to the aerosol size distribution, CCN number concentration was measured at supersaturations of $0.1 \%, 0.2 \%, 0.3 \%, 0.4 \%$ and $0.6 \%$, as reported by Saleeby et al. (2009), using the Droplet Measurement Technologies (DMT) CCN-100 (Roberts and Nenes, 2005). Observations from the SMPS and APS consistently showed particle counts between $N_{c n}=500$ and $N_{c n}=3000 \mathrm{~cm}^{-3}$ (for aerosol larger than the SMPS detection limit of $r=0.00435 \mu \mathrm{m}$ ) most often distributed uni-modally with distribution peaks smaller than $r=0.05 \mu \mathrm{m}$. The dominant Aitken-size mode (with respect to number) is most characteristic of a rural continental airmass as defined by Seinfeld and Pandis (2006).

For the purpose of obtaining realistic initial values for $r_{g}$ to initialize the aerosol field in RAMS, a single lognormal mode was fit to the aerosol size distribution samples from ISPA using the method of maximum likelihood. A time series of the resulting $r_{g}$ is shown in Fig. 4a plotted with $N_{c n}$ (Fig. $4 \mathrm{~b}$ ) at five-minute intervals. For the entire ISPA field study, the estimated average $r_{g}=0.018 \mu \mathrm{m}$ and varied little with 10th and 90th quantile values of $r_{g}=0.010 \mu \mathrm{m}$ and $r_{g}=0.028 \mu \mathrm{m}$. Total aerosol number, as measured by the SMPS and APS, showed more variation with a range of $N_{c n}=461$ to $10762 \mathrm{~cm}^{-3}$. The $N_{c n}$ dataset for the entire study period had a mean of $N_{c n}=1681 \mathrm{~cm}^{-3}$ but a median of $N_{c n}=1290 \mathrm{~cm}^{-3}$. Some of the samples exhibit an apparent second mode with a peak near $r=0.05 \mu \mathrm{m}$ containing a relatively small proportion of the aerosol number, also characteristic of the rural continental airmass. In these instances the fitted distribution will underestimate the number of larger particles that, due to their size, are more likely to activate droplets. However, because this second mode contains so few particles, it does not appear in the sampled size distribution when this is averaged over the entire study period. For the purpose of producing an estimated $r_{g}$ for model initialization, the single mode $r_{g}$ will be used.

With the combination of size-differentiated aerosol and droplet activation data, it is possible to estimate the $\kappa$ value of each ambient aerosol sample if an internal mixture is assumed. At a fixed supersaturation, knowledge of the critical radius, that separates the particles that activate from those that remain unactivated, implies a single value of $\kappa$ for internally mixed aerosol. With the CCN number concentration known, the critical radius (and subsequently $\kappa$ ) can be estimated from the aerosol size distribution samples. This method is similar to that used in CCN closure experiments in which, typically, an aerosol hygroscopicity is assumed and used to predict the $\mathrm{CCN}$ number concentration. Previous studies of this kind have suggested that variations in aerosol composition are the greatest source of error in achieving CCN closure (Bougiatioti et al., 2009). Here, we assume $\mathrm{CCN}$ closure exists and use this assumption to predict aerosol hygroscopicity. The $\mathrm{CCN}$ data sampled during ISPA at $0.3 \%$ supersaturation were used in this analysis. The DMT-CCN counter uses a temperature differential to create the necessary supersaturated environment. Measurements taken when the temperature differential was not stabilized were neglected. The remaining data were averaged over 5-minute periods and compared to a single corresponding SMPS and APS observation. The results of this analysis show very little variation in $\kappa$ estimated from the SPL measurements. For the entire field campaign, the average estimated $\kappa$ was 0.14 with 10th and 90th quantile values of $\kappa=0.08$ and $\kappa=0.18$. Past research in the Park Range area has found that sulfate aerosol plays a major role in local orographic cloud microphysics (e.g. Borys et al., 2000; Borys et al., 2003), but the ISPA measurements show a low hygroscopicity aerosol population, perhaps indicative of a dominant organic component. 
Table 2. Settings used for all RAMS sensitivity simulations.

\begin{tabular}{|c|c|c|c|c|c|}
\hline Setting & All grids & Grid 1 & Grid 2 & Grid 3 & Grid 4 \\
\hline Microphysics & $\begin{array}{l}\text { Two-moment bulk (Mey- } \\
\text { ers et al., 1997) }\end{array}$ & & & & \\
\hline Turbulence closure & $\begin{array}{l}\text { Horizontal: based on } \\
\text { Smagorinsky (1963) } \\
\text { Vertical: Mellor and } \\
\text { Yamada (1982) }\end{array}$ & & & & \\
\hline Radiation & $\begin{array}{l}\text { Two-stream (Harrington, } \\
\text { 1997) }\end{array}$ & & & & \\
\hline Surface boundary & $\begin{array}{l}\text { LEAF-2 (Walko et al., } \\
2000 \text { ) }\end{array}$ & & & & \\
\hline Cumulus Parameterization & & Kain and Fritsch (1993) & None & None & None \\
\hline Grid points $(\mathrm{X} \times \mathrm{Y})$ & & $62 \times 50$ & $54 \times 50$ & $97 \times 82$ & $114 \times 114$ \\
\hline Horizontal spacing & & $60 \mathrm{~km}$ & $15 \mathrm{~km}$ & $3 \mathrm{~km}$ & $0.75 \mathrm{~km}$ \\
\hline Center latitude $\left({ }^{\circ} \mathrm{N}\right)$ & & 40.0 & 40.3 & 40.2 & 40.46 \\
\hline Center longitude $\left({ }^{\circ} \mathrm{W}\right)$ & & 106.0 & 106.5 & 106.4 & 106.75 \\
\hline
\end{tabular}

\subsection{RAMS setup}

RAMS was set up, as in Saleeby et al. (2009), on four horizontal grids with two-way nesting. The grid arrangement and other important model parameters are given in Table 2. RAMS uses a sigma-z terrain-following vertical coordinate system set up, in this case, with 40 vertical levels. To increase the vertical resolution in the boundary layer, the lowest model level has a vertical grid spacing of $75 \mathrm{~m}$. This is stretched by a ratio of 1.12 for subsequent levels until reaching a maximum spacing of $750 \mathrm{~m}$. The North American Regional Reanalysis dataset was used to initialize the meteorological fields as well as nudge the lateral and model top boundary meteorology at 5-min intervals. Model aerosol number concentration was initialized in a horizontally-homogeneous, vertically-decreasing profile with a surface concentration of $N_{c n}=1500 \mathrm{~cm}^{-3}$. This value is slightly higher than the median concentration observed at SPL during ISPA. It was prescribed assuming that, since the $r_{g}$ observed during ISPA was near the lower detection limit of the SMPS instrument, the Aitken mode contained a portion of particles that were not large enough to be observed. Above the model level $150 \mathrm{~m}$ above ground, the initial aerosol number concentration decreases linearly to the model level $4000 \mathrm{~m}$ above ground. Above $4000 \mathrm{~m}$ a low, free-tropospheric number concentration $N_{c n}=100 \mathrm{~cm}^{-3}$ is assumed.

Twenty-one simulations were run with varied initial $r_{g}$ and $\kappa$. The initial values of $r_{g}$ and $\kappa$ remained constant throughout the entire respective simulation. The values of these parameters are shown in Table 3 for all simulations. Note that here we employ the entire range in $\kappa$ that is available in the droplet activation look-up tables and no longer restrict the analysis to typical continental values. All simulations were run for a duration of $42 \mathrm{~h}$ beginning at 00:00 GMT 11 February 2007 and ending at 18:00 GMT 12 February 2007. This time period captured the length of the storm system that began at around 06:00 GMT on 11 February and began to dissipate by 18:00 GMT on 12 February.

\subsection{Sensitivity simulations results}

It is expected that the riming efficiency, and resulting precipitation distribution, would be modulated by variations in the $\mathrm{CCN}$ number concentration flowing into the orographic cloud (Saleeby et al., 2009). How then do adjustments in aerosol hygroscopicity change the activated $\mathrm{CCN}$ number concentration for the particular orographic cloud conditions? A first check is shown with vertical profiles of initial model $\mathrm{CCN}$ number concentration at a supersaturation of $0.6 \%$ in Fig. 5. CCN number concentration is predicted at prescribed values of supersaturation by the inclusion of the separate updraft look-up table in the RAMS droplet activation scheme. The look-up table is comprised of the updraft speeds required to reach the prescribed supersaturation in the parcel model given the simulated $T, N_{c n}$ and $r_{g}$. In this case, $T$ is set to a constant $25^{\circ} \mathrm{C}$ for diagnosis of model $\mathrm{CCN}$ to approximate the temperature in the SPL CCN instrument. The vertical profiles in this case were diagnosed at a model grid point upwind of SPL for the B-simulations in which $r_{g}=0.020 \mu \mathrm{m}$, about the observed average value for the ISPA campaign. The majority of particles in simulation B10 would activate droplets at the prescribed supersaturation of $0.6 \%$ but this number decreases with decreasing $\kappa$. For simulations A1, $\mathrm{B} 1$ and $\mathrm{C} 1$ (not plotted) fewer than $5 \mathrm{~cm}^{-3}$ particles would activate droplets in RAMS at this supersaturation, even near the surface boundary. 
Table 3. RAMS sensitivity simulation names and initial values for $r_{g}$ and $\kappa$.

\begin{tabular}{|c|c|c|c|c|c|c|c|c|c|c|c|}
\hline Initial & $\kappa$ & 0.00001 & 0.001 & 0.01 & 0.03 & 0.06 & 0.1 & 0.2 & 0.4 & 0.6 & 1.28 \\
\hline \multicolumn{12}{|c|}{$r_{g}(\mu \mathrm{m})$} \\
\hline 0.010 & & A1 & A2 & A3 & A4 & A5 & A6 & A7 & A8 & A9 & A10 \\
\hline 0.020 & & B1 & B2 & B3 & B4 & B5 & B6 & B7 & B8 & B9 & B10 \\
\hline 0.040 & & $\mathrm{C} 1$ & B2 & $\mathrm{C} 3$ & $\mathrm{C} 4$ & C5 & $\mathrm{C} 6$ & C7 & $\mathrm{C} 8$ & C9 & $\mathrm{C} 10$ \\
\hline
\end{tabular}

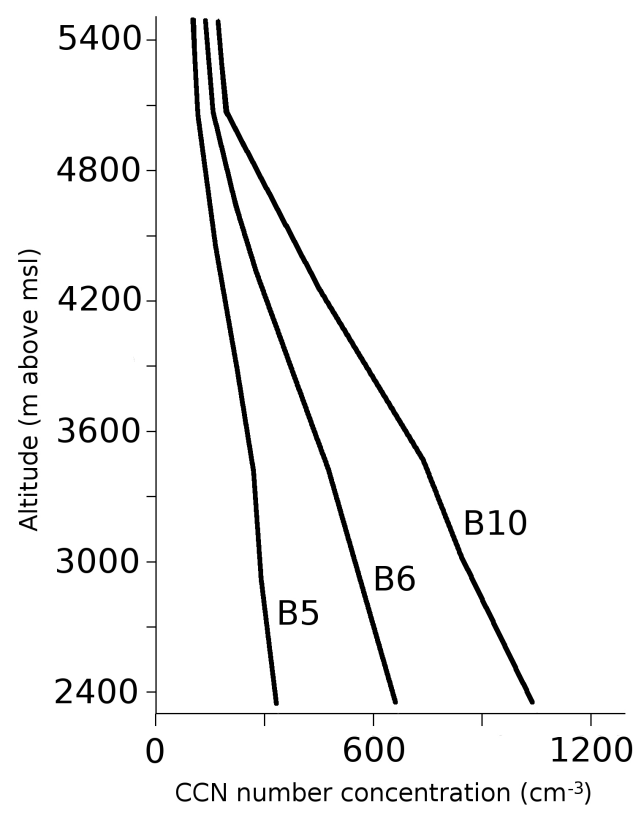

Fig. 5. Vertical profiles of CCN diagnosed from RAMS simulations B5, B6, and B10 for conditions of $0.6 \%$ supersaturation and $T=25^{\circ} \mathrm{C}$. The profiles were taken from $40.5^{\circ} \mathrm{N}$ and $107.0^{\circ} \mathrm{W}$ at 30 simulation minutes after the model initialization.

The simulated orographic flow strengthened as the model progressed into 12 February and reached peak intensity by 12:00 GMT on that day with updraft speeds generally greater than $1 \mathrm{~m} / \mathrm{s}$ along the windward side of the Park Range and exceeding $2 \mathrm{~m} / \mathrm{s}$ in many locations. These conditions, along with the prescribed $N_{c n}=1500 \mathrm{~cm}^{-3}$ put this case into the aerosol-limited regime as defined by Reutter et al. (2009), although areas with weaker updrafts would be classified into the transitional regime. Apart from predictions of sensitivity to $\kappa$ in these regimes, the aerosol-limited regime is characterized by high supersaturation. As a result, in some locations more droplets are activated in the model orographic cloud than were predicted for a supersaturation of $0.6 \%$ in Fig. 5. As air parcels enter the high updrafts forced by the topography, even the non-hygroscopic aerosol case $(\kappa=0.00001)$ produced $N_{d}$ values in excess of $700 \mathrm{~cm}^{-3}$ (Fig. 6a). The vertical cross-sections in Fig. 6 are shown at a latitude of $40.455^{\circ}$ and at $12: 00$ GMT on 12 February during the peak intensity of the storm. The differences between the $N_{d}$ in simulations B1 and B10 are significant. The high- $\kappa$ simulation, B10 (Fig. 6c), generates between one and two hundred more droplets per unit volume at its maximum and a larger area with $N_{d}$ values greater than $700 \mathrm{~cm}^{-3}$ than that shown in Fig. 6a for the low- $\kappa$ case. Also important to note are the smaller mean droplet diameters produced in simulations B7 (Fig. 6b) and B10 when compared to B1. Only mean droplet diameters larger than $10 \mu \mathrm{m}$ are plotted in Fig. 6 to highlight the areas where riming will take place, according to experimentally determined collection efficiencies (Pruppacher and Klett, 1997). Droplets located outside the $10 \mu \mathrm{m}$ threshold contour will not be collected by ice crystals to an appreciable degree.

The differences in mean droplet diameter for the range in $\kappa$ are greater for the simulations in group A shown in Fig. 6d-f. Large regions of mean droplet diameters near or below $10 \mu \mathrm{m}$ are predicted in simulation A10 (Fig. 6f) whereas Fig. 6d shows, in general, mean droplet diameters in excess of $10 \mu \mathrm{m}$ and areas of much larger droplets for A1. For A7, shown in Fig. 6e, the $N_{d}$ and mean droplet diameter fields are more similar to those of high- $\kappa$ conditions than low- $\kappa$ conditions. This is evidence that the greatest sensitivity to $\kappa$ in these simulations occurs below $\kappa=0.2$.

Increasing the value of $\kappa$ from near zero to 1.28 led to changes in the distribution of precipitation across the topographical barrier for all simulation groups. As shown in previous work, an increase in the $N_{d}$ leads to a decrease in windward precipitation and an increase in leeward precipitation, known as the spillover effect (Muhlbauer and Lohmann, 2008; Saleeby et al., 2009). The ratio of leeward precipitation to total orographic precipitation was proposed by Jiang and Smith (2003) as a single-value measure of the spillover effect. The spillover ratio was also used by Muhlbauer and Lohmann (2008).

To illustrate the spillover effect, the difference between total precipitation in simulations A1 and A10 is shown in Fig. 7 along with similar plots for $\mathrm{B} 1$ and $\mathrm{B} 10$, and $\mathrm{C} 1$ and $\mathrm{C} 10$. The location of the continental divide is plotted to show the approximate location of the ridge of the topography. The west to east direction of the strong cross-barrier flow that is necessary for sustaining the orographic cloud is indicated in Fig. 7 by an arrow. In Fig. 7a, a strong spillover effect is apparent. Precipitation is increased on the windward (western) 


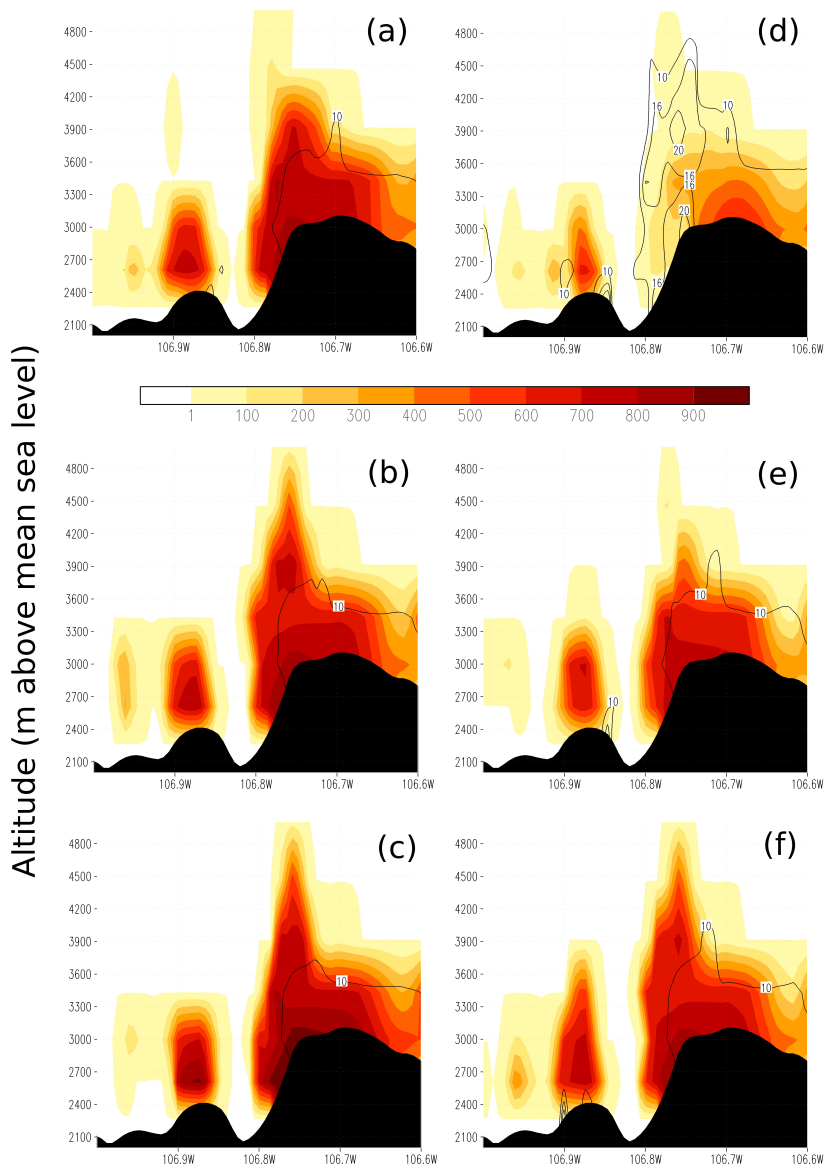

Fig. 6. Vertical cross-sections of $N_{d}$ (shaded; $\mathrm{cm}^{-3}$ ) and mean droplet diameter (contoured; $\mu \mathrm{m}$ ) for RAMS simulations (a) B1, (b) B7, (c) B10, (d) A1, (e) A7, (f) A10. Only mean droplet diameters above $10 \mu \mathrm{m}$ are contoured. The cross-section was taken at $40.455^{\circ} \mathrm{N}$ and terrain is blacked out.

side of the ridge for the low extreme in $\kappa$ when compared to the high extreme and decreased on the leeward (eastern) side. The magnitude of the difference, between 4 to $5 \mathrm{~mm}$ along the Park Range, accounts for about $10 \%$ of the total storm precipitation in this region, similar to that shown by Saleeby et al. (2009) for a change in initial $N_{c n}$ from $300 \mathrm{~cm}^{-3}$ to $1100 \mathrm{~cm}^{-3}$. Of course, this is only theoretical since a range in $\kappa$ such as that used to initialize A1 and A10 is not likely to be observed at SPL. When the precipitation fields are compared for the simulations based on the 10th and 90th quantiles in $\kappa$ estimated from the ISPA project (considered to be $\mathrm{A} 5, \mathrm{~B} 5, \mathrm{C} 5$, and A7, B7, C7), the differences are trivial.

When $r_{g}$ is increased in the model, as in the B and C simulations, the scale of the precipitation differences is diminished. For $r_{g}$ increased to $r_{g}=0.02 \mu \mathrm{m}$ (Fig. 7b), the differences between the high- $\kappa$ and low- $\kappa$ simulations are only about half of those shown for the smaller $r_{g}$. In Fig. 7c, the sensitivity to the change in $\kappa$ is even smaller and almost no enhancement of windward precipitation is shown. The di-
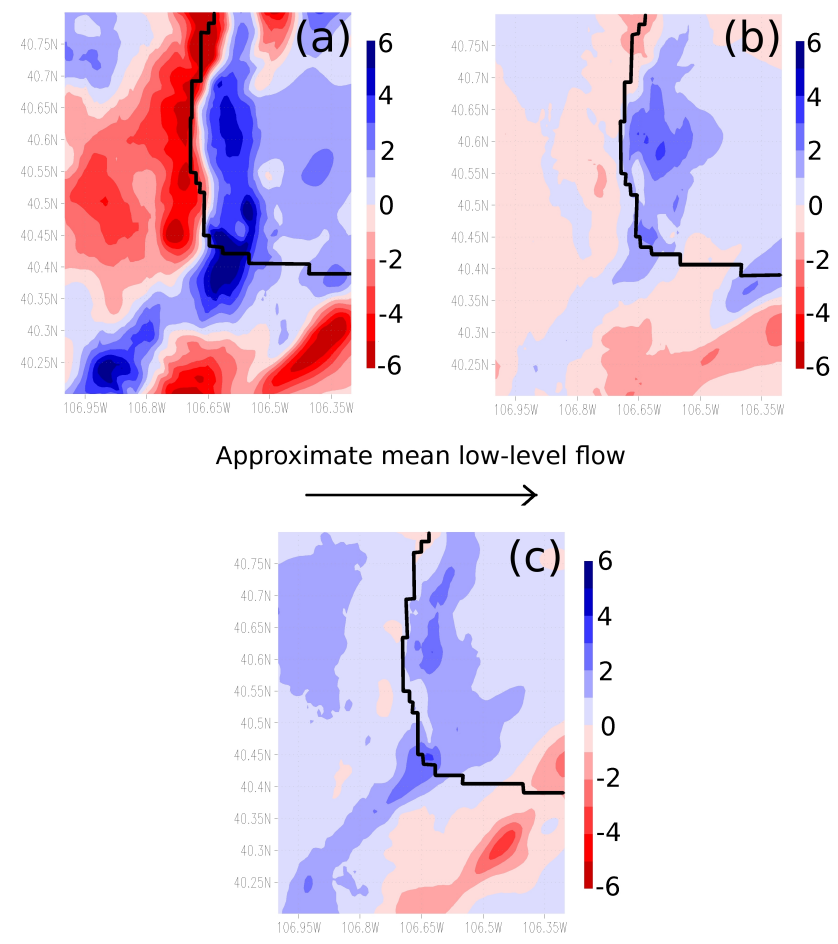

Fig. 7. The simulated difference in total storm-period precipitation (mm) between (a) A1-A10, (b) B1-B10, (c) C1-C10 is shown. Positive values (indicating, for example, areas that received more total precipitation in A1 than in A10) are shaded in blue. The continental divide is marked by the solid black line and the approximate direction of the mean low-level flow is indicated.

minishing sensitivity can be explained by the relationship between $\kappa$-dependence and the relative positions of $r_{c}$ and $r_{g}$, as shown in Sect. 2.3. As the aerosol size distribution moves to larger sizes, $r_{g}$ will necessarily increase with respect to $r_{c}$. In the model, this leads to weaker CCN sensitivity to changes in $\kappa$ and therefore, less impact on the simulated orographic cloud. It is important to note that because of the theoretically sharp threshold in droplet size that determines riming rate, the spillover will be greatest when changes in $N_{d}$ lead to droplet size changes above this threshold size. Cases for which $N_{d}$ is large will appear insensitive to variations in $N_{d}$ even for large changes in activated fraction.

As a more quantitative measure of the precipitation redistribution, the spillover ratio is applied. The leeward precipitation in this case was computed as the sum of all precipitation that fell during the storm period to the east of the continental divide, west of $106.3^{\circ} \mathrm{W}$, and between $40.4^{\circ} \mathrm{N}$ and $40.8^{\circ} \mathrm{N}$, per unit area. Total orographic precipitation was defined as precipitation, per unit area, that fell between those same latitudes and between $106.3^{\circ} \mathrm{W}$ and $107.0^{\circ} \mathrm{W}$. The spillover ratios for all simulations are shown in Table 4 . As expected from the analysis in Fig. 7, the spillover ratio changed the most for the A group of simulations. In all simulation groups, the spillover ratio was apparently most 
Table 4. Spillover ratio values for all RAMS sensitivity simulations.

\begin{tabular}{llllllllllll}
\hline Simulation & Number & 1 & 2 & 3 & 4 & 5 & 6 & 7 & 8 & 9 & 10 \\
\hline Group & & & & & & & & & & & \\
A & 0.366 & 0.362 & 0.389 & 0.396 & 0.398 & 0.398 & 0.398 & 0.400 & 0.400 & 0.401 \\
B & 0.391 & 0.390 & 0.400 & 0.400 & 0.400 & 0.399 & 0.399 & 0.399 & 0.400 & 0.402 \\
C & 0.398 & 0.402 & 0.402 & 0.402 & 0.404 & 0.401 & 0.402 & 0.403 & 0.402 & 0.404 \\
\hline
\end{tabular}

sensitive to variations in the lowest values of $\kappa$, below the range of $\kappa$ values estimated from the ISPA-II data.

In this study the role of variations in ice crystals was given little attention, yet these variations have the potential to determine the precipitation distribution in modeling studies of mixed-phase clouds. Muhlbauer and Lohmann (2009) introduced IN into idealized simulations of mixed-phase orographic clouds and found that increased number concentrations of IN can lead to an increase in total storm precipitation. When internally mixed aerosol are considered, particles are more likely to act as CCN than IN and the reduced riming described in the current study is reproducible. Still, the interactions between ice crystals and cloud droplets in these mixed-phase clouds are complex and still under investigation. These interactions may lead to variations in storm precipitation that are not predicted by the liquid-phase results put forth in this study.

\section{Conclusions}

Approaches for simplifying $\mathrm{CCN}$ predictions for application in mesoscale and larger-scale models are needed. Ideally, simplifications could be made that permit classification of aerosol populations into composition-dependent and non-composition-dependent as a function of observable environmental parameters. Previous studies have shown an apparent tendency for composition-dependence in lowsupersaturation conditions (Ervens et al., 2007; Gunthe et al., 2009). Reutter et al. (2009) defined regimes that are consistent with this hypothesis. By simulating the ascent of aerosol-laden air parcels we have also found that these environments will exhibit more sensitivity to changes in aerosol hygroscopicity because lower supersaturation typically leads to a higher $r_{c}$. However, this is not the complete picture. The parcel model results show that, because of the nature of the lognormal distribution assumed in the model, low supersaturation environments could potentially exhibit only small composition-dependence for size distributions with the larger initial mode diameters. And at high supersaturations the composition-dependence could be important if the size distribution median radius is more characteristic of a small Aitken mode. In reaching this conclusion, internally mixed aerosols with constant hygroscopicity over variable particle size were assumed. As a consequence, none of the complexities associated with external mixtures were examined in this study.

Uni-modal, Aitken mode-size aerosol size distributions were consistently sampled at SPL during the ISPA campaign. Therefore, despite the high supersaturations predicted by RAMS, a simulated orographic snowstorm case from the study period showed some sensitivity, evident as increased spillover precipitation, to extreme changes in the model aerosol hygroscopicity as represented by the $\kappa$ parameter. The differences in precipitation amount and distribution were similar to those seen in simulations of the same case by Saleeby et al. (2009) in which $N_{c n}$ was varied. However, the lack of variability of $\kappa$ and $r_{g}$, as estimated from SPL observations, suggest only a small role for these quantities in this environment. This leads to the supposition that for these high supersaturation clouds and for rural continental aerosol populations, consideration of the variability of aerosol composition might safely be neglected for purposes of modeling the liquid-phase cloud physics.

Similar sensitivity approximations could be applied to other cloud regimes for the purpose of increasing the efficiency of model representations. In areas where sufficient observations are not available, it is instead useful to know what information needs to be gathered to make an educated assumption about the sensitivity of such clouds to changes in aerosol hygroscopicity. In light of the parcel model results described in this paper, any such arrangement should include consideration of the size distribution, as characterized by the median radius.

Acknowledgements. This research was supported by the National Science Foundation grant ATM-0835421. The authors would like to thank Gannet Haller and Ian McCubbin of the Desert Research Institute, as well as the Steamboat Ski and Resort Corporation for support during the ISPA field campaign. We also thank two anonymous reviewers for their constructive comments that helped improve this paper.

Edited by: P. Spichtinger 


\section{References}

Andreae, M. O. and Rosenfeld, D.: Aerosol-cloudprecipitation interactions. Part 1. The nature and sources of cloud-active aerosols, Earth-Sci. Rev., 89, 13-41, doi:10.1016/j.earscirev.2008.03.001, 2008.

Anttila, T. and Kerminen, V.-M.: On the contribution of Aitken mode particles to cloud droplet populations at continental background areas - a parametric sensitivity study, Atmos. Chem. Phys., 7, 4625-4637, doi:10.5194/acp-7-4625-2007, 2007.

Borys, R. D., Lowenthal, D. H., Cohn, S. A., and Brown, W. O. J.: Mountaintop and radar measurements of anthropogenic aerosol effects on snow growth and snowfall rate, Geophys. Res. Lett., 30(10), 1538, doi:10.1029/2002GL016855, 2003.

Borys, R. D., Lowenthal, D. H., and Mitchell, D. L.: The relationship among cloud microphysics, chemistry, and precipitation rate in cold mountain clouds, Atmos. Environ., 34, 2593-2602, 2000.

Borys, R. D. and Wetzel, M.: Storm Peak Laboratory: A research, teaching, and service facility for the atmospheric sciences, B. Am. Meteorol. Soc., 78(10), 2115-2123, 1997.

Bougiatioti, A., Fountoukis, C., Kalivitis, N., Pandis, S. N., Nenes, A., and Mihalopoulos, N.: Cloud condensation nuclei measurements in the marine boundary layer of the Eastern Mediterranean: CCN closure and droplet growth kinetics, Atmos. Chem. Phys., 9, 7053-7066, doi:10.5194/acp-9-7053-2009, 2009.

Brown, P. N., Byrne, G. D., and Hindmarsh, A. C.: Vode A variable-coefficient ODE solver, SIAM J. Sci. Stat. Comp., 10(5), 1038-1051, 1989.

Cantrell, W., Shaw, G., Cass, G. R., Chowdhury, Z., Hughes, L. S., Prather, K. A., Guazzotti, S. A., and Coffee, K. R.: Closure between aerosol particles and cloud condensation nuclei at Kaashidhoo Climate Observatory, J. Geophys. Res.-Atmos., 106, 28711-28718, 2001.

Cheng, W. Y. Y., Carrio, G., Cotton, W. R., and Saleeby, S. M.: Influence of cloud condensation and giant cloud condensation nuclei on the development of precipitating trade wind cumuli in a large eddy simulation, J. Geophys. Res.-Atmos., 114, D08201, doi:10.1029/2008JD011011, 2009.

Cotton, W. R., Pielke Sr., R. A., Walko, R. L., Liston, G. E., Tremback, C. J., Jiang, H., McAnelly, R. L., Harrington, J. Y., Nicholls, M. E., Carrio, G. G., and McFadden, J. P.: RAMS 2001: Current status and future directions, Meteorol. Atmos. Phys., 82, 5-29, 2003.

Cubison, M. J., Ervens, B., Feingold, G., Docherty, K. S., Ulbrich, I. M., Shields, L., Prather, K., Hering, S., and Jimenez, J. L.: The influence of chemical composition and mixing state of Los Angeles urban aerosol on CCN number and cloud properties, Atmos. Chem. Phys., 8, 5649-5667, doi:10.5194/acp-8-5649-2008, 2008.

Dusek, U., Frank, G. P., Hildebrandt, L., Curtius, J., Schneider, J., Walter, S., Chand, D., Drewnick, F., Hings, S., Jung, D., Borrmann, S., and Andreae, M. O.: Size matters more than chemistry for cloud-nucleating ability of aerosol particles, Science, 312, 1375-1378, 2006.

Eidhammer, T., DeMott, P. J., and Kreidenweis, S. M.: A comparison of heterogeneous ice nucleation parameterizations using a parcel model framework, J. Geophys. Res.-Atmos., 114, D06202, doi:10.1029/2008JD011095, 2009.

Ervens, B., Cubison, M., Andrews, E., Feingold, G., Ogren, J. A., Jimenez, J. L., DeCarlo, P., and Nenes, A.: Prediction of cloud condensation nucleus number concentration using measurements of aerosol size distributions and composition and light scattering enhancement due to humidity, J. Geophys. Res.-Atmos., 112, D10S32, doi:10.1029/2006JD007426, 2007.

Feingold, G.: Modeling of the first indirect effect: Analysis of measurement requirements, Geophys. Res. Lett., 30(19), 1997, doi:10.1029/2003GL017967, 2003.

Gunthe, S. S., King, S. M., Rose, D., Chen, Q., Roldin, P., Farmer, D. K., Jimenez, J. L., Artaxo, P., Andreae, M. O., Martin, S. T., and Pöschl, U.: Cloud condensation nuclei in pristine tropical rainforest air of Amazonia: size-resolved measurements and modeling of atmospheric aerosol composition and CCN activity, Atmos. Chem. Phys., 9, 7551-7575, doi:10.5194/acp-9-75512009, 2009.

Harrington, J. Y.: The effects of radiative and microphysical processes on simulated warm and transition season Arctic stratus, Ph.D. thesis, Colorado State University, Colorado, USA, 289 pp., 1997.

Heymsfield, A. J. and Sabin, R. M.: Cirrus crystal nucleation by homogeneous freezing of solution droplets, J. Atmos. Sci, 46, 2252-2264, 1989.

Hudson, J. G.: Variability of the relationship between particle size and cloud-nucleating ability, Geophys. Res. Lett., 43, L08801, doi:10.1029/2006GL028850, 2007.

Jiang, Q. and Smith, R. B.: Cloud timescales and orographic precipitation, J. Atmos. Sci., 60, 1543-1560, 2003.

Kain, J. S. and Fritsch, J. M.: Convective parameterization for mesoscale models: The Kain-Fritsch scheme, Meteor. Mon., 46, 165-170, 1993.

Lynn, B., Khain, A., Rosenfeld, D., and Woodley, W.: Effects of aerosols on precipitation from orographic clouds, J. Geophys. Res.-Atmos., 112, D10225, doi:10.1029/2006JD007537, 2007.

McFiggans, G., Artaxo, P., Baltensperger, U., Coe, H., Facchini, M. C., Feingold, G., Fuzzi, S., Gysel, M., Laaksonen, A., Lohmann, U., Mentel, T. F., Murphy, D. M., O’Dowd, C. D., Snider, J. R., and Weingartner, E.: The effect of physical and chemical aerosol properties on warm cloud droplet activation, Atmos. Chem. Phys., 6, 2593-2649, doi:10.5194/acp-6-2593-2006, 2006.

Medina, J., Nenes, A., Sotiropoutlou, R.-E. P., Cottrell, L. D., Ziemba, L. D., Beckman, P. J., and Griffin, R. J.: Cloud condensation nuclei closure during the international Consortium for Atmospheric Research on Transport and Transformation 2004 campaign: Effects of size-resolved composition, J. Geophys. Res.Atmos., 112, D10S31, doi:10.1029/2006JD007588, 2007.

Mellor, G. L. and Yamada, T.: Development of a turbulence closure model for geophysical fluid problems, Rev. Geophys. Space Ge., 20, 851-875, 1982.

Meyers, M. P., Walko, R. L., Harrington, J. Y., and Cotton, W. R.: New RAMS cloud microphysics parameterization. Part II. The two-moment scheme, Atmos. Res., 45, 3-39, 1997.

Muhlbauer, A. and Lohmann, U.: Sensitivity studies of the role of aerosols in warm-phase orographic precipitation in different dynamical flow regimes, J. Atmos. Sci., 65, 2522-2542, doi:10.1175/2007JAS2492.1, 2008.

Muhlbauer, A. and Lohmann, U.: Sensitivity studies of aerosolcloud interactions in mixed-phase orographic precipitation, J. Atmos. Sci., 66, 2517-2538, doi:10.1175/2009JAS3001.1, 2009.

Petters, M. D. and Kreidenweis, S. M.: A single parameter repre- 
sentation of hygroscopic growth and cloud condensation nucleus activity, Atmos. Chem. Phys., 7, 1961-1971, doi:10.5194/acp-71961-2007, 2007.

Pruppacher, H. R. and Klett, J. D.: Microphysics of Clouds and Precipitation, Dordrecht, The Netherlands, Kluwer Academic Publishers, 954 pp., 1997.

Quinn, P. K., Bates, T. S., Coffman, D. J., and Covert, D. S.: Influence of particle size and chemistry on the cloud nucleating properties of aerosols, Atmos. Chem. Phys., 8, 1029-1042, doi:10.5194/acp-8-1029-2008, 2008.

Rauber, R. M., Grant, L. O., Feng, D., and Snider, J. B.: The characteristics and distribution of cloud water over the mountains of Northern Colorado during wintertime storms. Part I: Temporal variations, J. Clim. Appl. Meteorol., 25, 468-488, 1986.

Reutter, P., Su, H., Trentmann, J., Simmel, M., Rose, D., Gunthe, S. S., Wernli, H., Andreae, M. O., and Pöschl, U.: Aerosoland updraft-limited regimes of cloud droplet formation: influence of particle number, size and hygroscopicity on the activation of cloud condensation nuclei (CCN), Atmos. Chem. Phys., 9, 7067-7080, doi:10.5194/acp-9-7067-2009, 2009.

Rissman, T. A., Nenes, A., and Seinfeld, J. H.: Chemical amplification (or dampening) of the Twomey effect: Conditions derived from droplet activation theory, J. Atmos. Sci, 61, 919-930, 2004.

Rissman, T. A., VanReken, T. M., Wang, J., Gasparini, R., Collins, D. R., Jonsson, H. H., Brechtel, F. J., Flagan, R. C., and Seinfeld, J. H.: Characterization of ambient aerosol from measurements of cloud condensation nuclei during the 2003 Atmospheric Radiation Measurement Aerosol Intensive Observational Period at the Southern Great Plains site in Oklahoma, J. Geophys. Res.Atmos., 111, D05S11, doi:10.1029/2004JD005695, 2006.

Roberts, G. C. and Nenes, A.: A continuous-flow streamwise thermal-gradient $\mathrm{CCN}$ chamber for atmospheric measurements, Aerosol Sci. Technol., 39(3), 206-221, 2005.

Saleeby, S. M., Cheng, W. Y. Y., and Cotton, W. R.: New developments in the Regional Atmospheric Modeling System suiTable for simulations of snowpack augmentation over complex terrain, J. Weather Mod., 39, 37-49, 2007.
Saleeby, S. M. and Cotton, W. R.: A large-droplet mode and prognostic number concentration of cloud droplets in the Colorado State University Regional Atmospheric Modeling System (RAMS). Part I: Module descriptions and supercell test simulations, J. Appl. Meteorol., 43, 182-195, 2004.

Saleeby, S. M. and Cotton, W. R.: A binned approach to clouddroplet riming implemented in a bulk microphysics model, J. Appl. Meteorol., 47, 694-703, doi:10.1175/2007JAMC1664.1, 2008.

Saleeby, S. M., Cotton, W. R., Lowenthal, D., Borys, R. D., and Wetzel, M. A.: Influence of cloud condensation nuclei on orographic snowfall, J. Appl. Meteorol. Clim., 48, 903-922, doi:10.1175/2008JAMC1989.1, 2009.

Seinfeld, J. H. and Pandis, S. N.: Atmospheric Chemistry and Physics, Wiley \& Sons, Hoboken, New Jersey, USA, 1203 pp., 2006.

Smagorinsky, J.: General circulation experiments with the primitive equations. Part I: The basic experiment, Mon. Weather Rev., 125, 1489-1506, 1963.

Twomey, S.: The nuclei of natural cloud formation, Part II: The supersaturation in natural clouds and the variation of cloud droplet concentration, Geofis. Pura. Appl., 43, 243-249, 1959.

van den Heever, S. C. and Cotton, W. R.: Urban aerosol impacts on downwind convective storms, J. Appl. Meteorol. Clim., 46, 828-850, 2007.

Walko, R. L., Band, L. E., Baron, J., Kittel, T. G. F., Lammers, R., Lee, T. J., Ojima, D., Pielke Sr., R. A., Taylor, C., Tague, C., Tremback, C. J., and Vidale, P. J.: Coupled atmosphericbiophysics-hydrology models for environmental modeling, J. Appl. Meteorol., 34, 994-999, 2000. 